\title{
The Neuroectodermal Subtypes of Chiari Malformation: Long-term Results
}

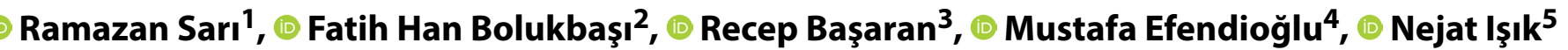 \\ ${ }^{1}$ Department of Neurosurgery, Acibadem Maslak Hospital, Istanbul, Turkey \\ ${ }^{2}$ Department of Neurosurgery, Rumeli University REYAP Hospital, Collage of Health Sciences, Istanbul, Turkey \\ ${ }^{3}$ Department of Neurosurgery, University of Health Sciences Turkey, Sancaktepe Prof. Dr. Ilhan Varank Health Aplication and Research \\ Center, Istanbul, Turkey \\ ${ }^{4}$ Department of Neurosurgery, University of Health Sciences Turkey, Haydarpaşa Numune Health Application and Research Center, \\ Istanbul, Turkey \\ ${ }^{5}$ Department of Neurosurgery, Istanbul Medeniyet University Goztepe Training and Research Hospital, Istanbul, Turkey
}

\begin{abstract}
Introduction: Chiari malformations (CMs) are a heterogeneous group of disorders defined by anatomic anomalies of the cerebellum, brainstem, and craniovertebral junction (CVJ). This study aims to establish the de-mographic and clinical features, incidence, surgical procedures, and outcomes in large series of CMs, to investi-gate whether CM-0 is a subgroup of CM, Chiari 1 and 1.5 are different pathologies.

Methods: In this study, all of the patients were evaluated and operated on for CM between 1985 and 2016. The patients were grouped into various subtypes. Demographic data, additional diseases, clinical features, surgical procedures, complications and outcomes were recorded.

Results: In this study, 55 patients who underwent various surgical procedures were evaluated. Their mean age was $0.72 \pm 1.17$. We detected 26 cases of CM-2 (47.3\%), 16 cases of CM-3 (29.1\%) and 13 cases of CM-4 (23.6\%). When Chiari subtypes were compared, there were statistically significant differences in additional dis-eases, symptom duration, neuro examination, complication rate and hospital stay.

Discussion and Conclusion: The findings obtained in this study suggest that the long hospital stay, the presence of SM and short symptom duration are associated with worse outcomes. The dura repair is the most important stage of surgery. Dural tear (CSF fistule) increases the complication rate and mean hospital stay and also causes the worse outcome. Therefore, the surgeon should spend more time on dura repair.

Keywords: Chiari malformation; Chiari subtypes; Chiari definition; complication; neuroectodermal; surgery.
\end{abstract}

Cof hiari malformations (CMs) are a heterogeneous group of disorders defined by anatomic anomalies of the cerebellum, brainstem, and craniovertebral junction (CVJ), along with the downward displacement of the cerebellum, sometimes accompanied by the lower medulla en-tering into the spinal canal ${ }^{[1]}$. CMs were first described by John
Cleland in $1883^{[2,3]}$. In 1891, they were classified by Hans Chiari into four groups ${ }^{[4]}$.

There are no population-based studies on the incidence or prevalence of CMs. In clinical se-ries in the literature, its prevalence has been estimated to be between 0.1 and $0.5 \%{ }^{[5]}$, but it is possible that higher rates could have re- 
sulted from the more widespread use of MRI (magnetic resonance imaging) in recent years. Another study estimated a prevalence of $0.77 \%$ based on the total patient population undergoing MRI of the head at a tertiary care center over a pe-riod of 3.5 years.

The etiology and pathophysiology of Chiari are not wellunderstood. CM-1 malformation is assumed to occur due to genetic pathologies ${ }^{[6,7]}$. CM-1 malformation is believed to originate from the para-axial mesoderme ${ }^{[8,9]}$. CM-2, CM-3, and $\mathrm{CM}-4$ are believed to originate in the neuroectodermal tissue ${ }^{[10]}$. Rarely, spina bifida occulta is seen in CM-1 cases. In such cases, it may originate in the neuroectoderme ${ }^{[11] .}$

This study aims to reveal the management and long term results of neuroectodermal originated Chiari malformations.

\section{Materials and Methods}

\section{Definitions}

- CM-2 involves the downward displacement of the cerebellar vermis and tonsils, brainstem malformation with meningomyelocele (MM), and a beaked tectum on neuroimaging (Fig. 1) ${ }^{[1,10]}$;

- CM-3 is rare and combines a small posterior fossa with a high cervical or occipital encephalocele, generally with the displacement of cerebellar structures into the encephalocele and the inferior displacement of the brain-

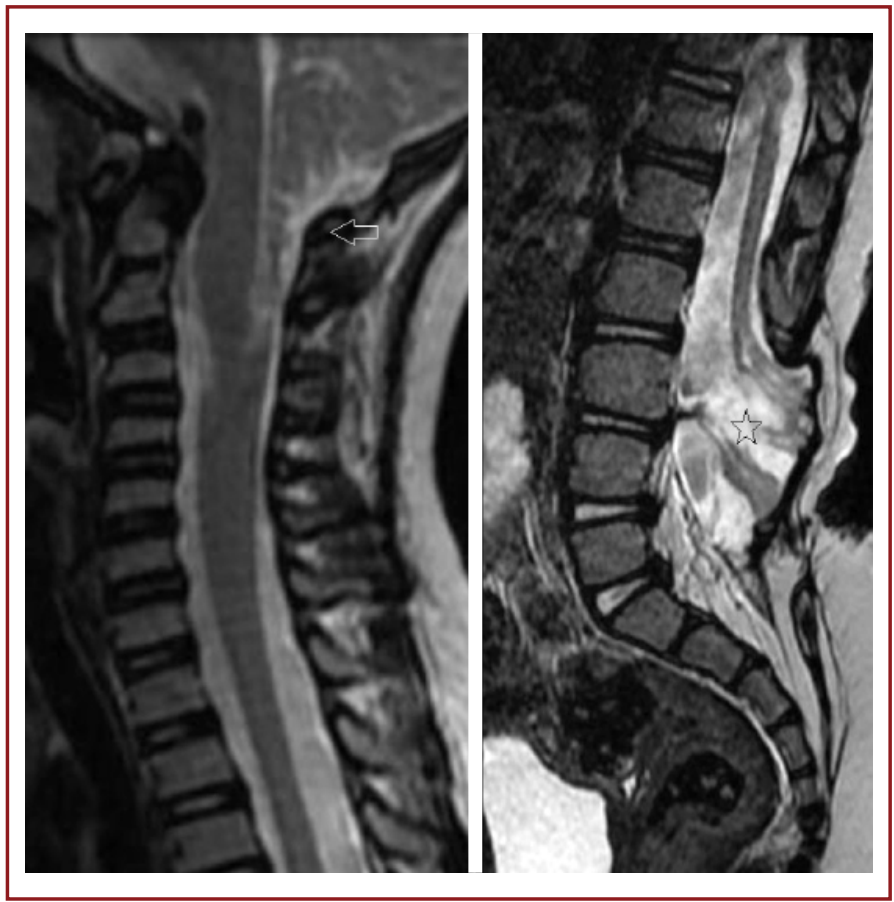

Figure 1. CM-2 involves the downward displacement of the cerebellar vermis and tonsils, brainstem malformation (arrow) with meningomyelocele (star), and a beaked tectum on neuroimaging. stem into the spinal canal (Fig. 2) ${ }^{[1,10]}$;

- CM-4 is now considered an obsolete term that describes cerebellar hypoplasia unrelated to the other CMs. CM-4 involves reduced posterior fossa, herniation of posterior fossa component, and low tentorium ${ }^{[1,10]}$.

\section{Patients}

All patients were evaluated in our department or referred to our department from peripheral hospitals. From 1985 to 2016,55 patients ( 30 females and 25 males) underwent various surgical procedures. All surgical procedures were applied to our clinics. Inclusion criteria were as follows: 1) operation for meningomyelocele, myelochisis, hydrocephalus and encephalocele, 2) available data. Exclusion criteria were as follows: 1 ) incomplete data and 2) occipitocervi-cal instability.

\section{Demographic Data}

We recorded the age, sex, and additional diseases of the patients. All patients underwent MRIs of the brain, the craniocervical junction, and the entire spine. Magnetic resonance imag-ings (MRIs) were evaluated to investigate the presence and extent of tonsillar herniation, syringomyelia, or syringobulbia. Patients were divided according to $\mathrm{CM}$ subtypes. The presence of Syringomyelia (SM) was recorded. We

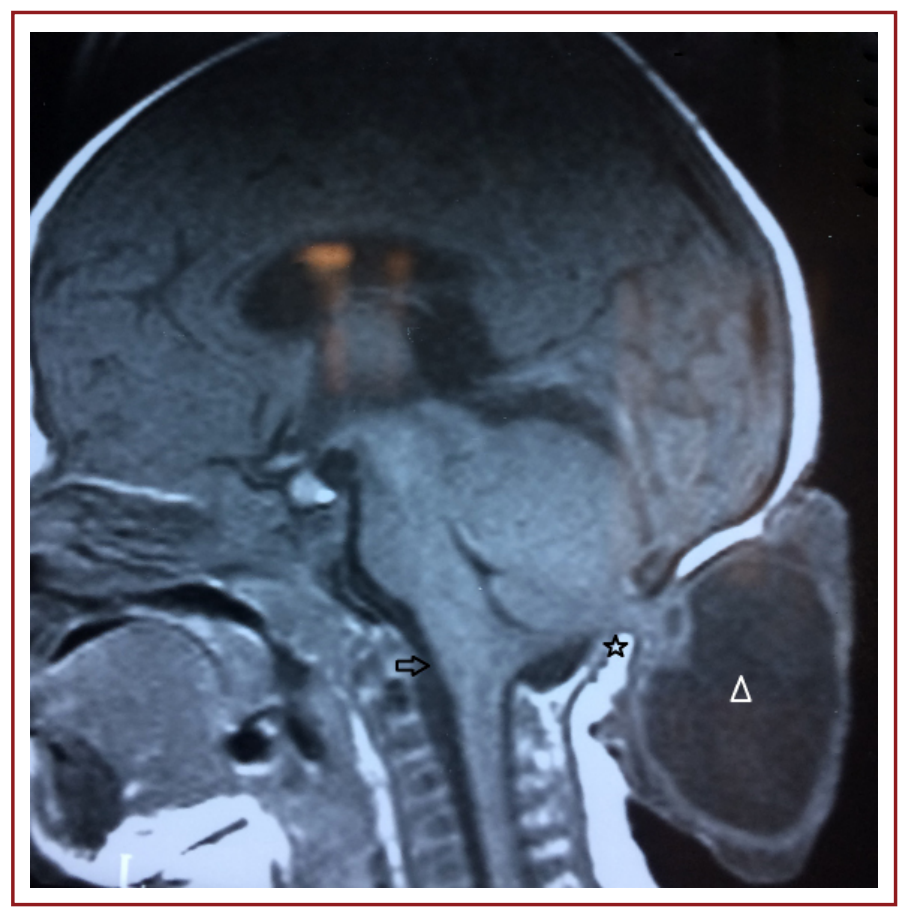

Figure 2. CM-3 is rare and combines a small posterior fossa with a high cervical or occipital encephalocele (triangle), generally with the displacement of cerebellar structures into the en-cephalocele (star) and the inferior displacement of the brainstem into the spinal canal (arrow). 
performed contrastenhanced MRI for patients with SMto rule out the possibility of an intramedullary spinal tumor. MRI is also important when evaluating postoperative changes after the treatment of the CMs ${ }^{[12]}$. The clinical characteristics and symptom duration of patients were evaluated retrospectively. Symptoms and signs were divided into eighteen groups as follows: headache, vertigo/dizziness, breathing prob-lems, cephalocele, MM, head enlargement, seizure, microcephaly, meningitis, and a lack of tranquility. The neurological examination results were divided into two categories: normal and abnormal. Abnormal results were noted. The surgical procedure, the nature of any potential complications, and the time elapsed since surgery was recorded. We evaluated and noted the symptoms before and six months after surgery. We also noted the duration of the hospital stay, follow up and also the outcome.

\section{Statistical Analysis}

Following data collection, the data were analyzed using IBM SPSS. Descriptive statistics, specifically range, mean, and standard deviation, were calculated for each parameter. Normality was assessed using the Kolmogorov-Smirnov test. For normal distributions, mean differences were assessed using independent-sample Student's t-tests and Spearman's rho. Significance was indicated by a two-tailed test with $p$-value $<p=0.05$ and $95 \%$ confidence intervals. One-way ANOVA, Mann-Whitney $U$, and Kruskal Wallis tests were used for abnormal dis-tributions.

\section{Results}

In our study, we evaluated 55 cases with CM assessed in our hospital between 1985 and 2016. Ages ranged from one day to five months, and the mean age was $0.72 \pm 1.17$ months. Demo-graphic and clinical features of all cases included in our study, along with the postoperative findings are summarized in Table 1. Our study includes detailed information on the features of Chiari malformations. Distribution of Chiari malformations, neuroexamination, accompanying diseases, applied surgical procedures and surgical complications are summa-rized in Table 2.

Chiari subtypes were divided into CM-2 in 26 (47.3\%), CM-3 in $16(29.1 \%)$, and CM-4 in 13 (23.6\%) cases (Table 2). The distribution of sex, presence and distribution of additional dis-ease, neurological abnormalities and complications according to CM subtypes are shown in Table 3.

Among Chiari subtypes, we detected statistically significant differences image $(p=0.026)$, additional diseases $(p<0.01)$, symptom duration $(p=0.002)$, neurological abnormality $(p=0.02)$, complication rate $(p=0.023)$, and hospital stay ( $\mathrm{p}=0.097$ ) (Table 4).

Additional diseases were seen more frequently in $\mathrm{CM}-2$ $(75.7 \%, p<0.01)$. Symptom duration and hospital stay were found longer in CM-3 (10.25 \pm 11.7 days).

Hospital stays were found longer in patients who underwent MM+VPS (9.31 \pm 4.96 days) than MM alone $(5.3 \pm 2.06$ days) $(p=0.012)$.

Table 1. Summary of the demographic and clinical features and also postoperative findings in all patients of the neuroectodermal Chiari malformations

\begin{tabular}{|c|c|c|c|c|}
\hline & $\mathbf{n}$ & Minimum-Maximum & Mean \pm SD & \\
\hline Age (years) & 55 & 1 day- 5 years & $0.72 \pm 1.17$ & \\
\hline Sex & 55 & & & $\mathrm{~F}: 30$ (54.5\%), M: 25 (25.5\%) \\
\hline Additional disease & 55 & & & Yes: 33 (60\%) \\
\hline Syringomyelia (SM) & 55 & & & Yes: 4 (7.3\%) \\
\hline Muscle weakness & 55 & & & $11(20 \%)$ \\
\hline Breath problems & 55 & & & $31(1.8 \%)$ \\
\hline Cephalocele & 55 & & & $16(29.1 \%)$ \\
\hline Meningom yeleocele & 55 & & & $26(47.3 \%)$ \\
\hline Head enlargement & 55 & & & $24(43.6 \%)$ \\
\hline Seizure & 55 & & & $1(1.8 \%)$ \\
\hline Microcephaly & 55 & & & $1(1.8 \%)$ \\
\hline Meningitis & 55 & & & $3(5.5 \%)$ \\
\hline Lack of tranquility & 55 & & & $4(7.3 \%)$ \\
\hline Neurological abnormality & 55 & & & Yes: $15(27.3 \%)$ \\
\hline Symptoms duration (months) & 55 & $1-72$ & $7.8 \pm 12.5$ & \\
\hline Complication & 55 & & & Yes: 9 (16.4\%) \\
\hline Hospital stay (day) & 55 & $1-59$ & $10.81 \pm 11.42$ & \\
\hline
\end{tabular}


Table 2. Summary of the distribution of (A) Chiari malformation subtypes, (B) additional disease, (C) neuroex-amination, (D) surgical procedures and (E)complication types in all patients of neuroectodermal Chiari malfor-mation

\section{Chiari Malformation (CM) Subtypes}

\begin{tabular}{lcc}
\hline (A) & $\mathbf{n}$ & Percent (\%) \\
CM-2 & 26 & 47.3 \\
CM-3 & 16 & 29.1 \\
CM-4 & 13 & 23.6 \\
Total & 55 & 100.00 \\
(B) & $\mathbf{n}$ & Percent (\%) \\
\cline { 2 - 3 } Arachnoid cyst (AC) & 7 & 21 \\
Split cord syndrome (SCS) & 1 & 3 \\
Fibrous dysplasia (FD) & 2 & 6 \\
Klippel Feil syndrome & 1 & 3 \\
Platybasia & 7 & 21 \\
Bl and platibasia & 3 & 9 \\
Scoliosis & 12 & 37 \\
Total & 33 & 100 \\
Neuroexamination & &
\end{tabular}

Neuroexamination

\begin{tabular}{lcc}
\hline (C) & $\mathbf{n}$ & Percent (\%) \\
\cline { 2 - 3 } normal & 40 & 72.7 \\
lower CN sign & 1 & 1.8 \\
paraparesis & 5 & 9.1 \\
paraplegia & 9 & 16.4 \\
Total & 55 & 100.00 \\
Surgical Procedures & &
\end{tabular}

\section{Surgical Procedures}

\begin{tabular}{lcc}
\hline (D) & $\mathbf{n}$ & Percent (\%) \\
\cline { 2 - 3 } Encephalocele (EC) excision & 10 & 18.1 \\
EC excision+VPS & 3 & 5.5 \\
meningomyelocele (MM) & 13 & 23.6 \\
VPS+MM & 13 & 23.6 \\
EC excision +CVD & 1 & 1.8 \\
EC excision + craniosynostosis & 1 & 1.8 \\
EC excision +VPS+MM & 1 & 1.8 \\
cytoperitoneal shunt (CPS) & 13 & 23.6 \\
Total & 55 & 100.00 \\
Complication Types & & \\
\hline (E) & $\mathbf{n}$ & Percent (\%) \\
\cline { 2 - 3 } CSF fistula & 3 & 33.3 \\
Pneumocephalus (PC) & 2 & 22.2 \\
CNS infection & 1 & 11.1 \\
Wound infection & 1 & 11.1 \\
Shunt dysfunction & 2 & 22.2 \\
Total & 9 & 100 \\
\hline
\end{tabular}

When evaluating outcomes as "better, same, worse, longer hospital stay" is associated with worse outcomes $(p<0.01)$. When evaluating outcomes as "better" or "worse," the presence of SM $(p=0.024)$ and shorter symptom duration $(p<0.01)$ seem to affect the outcomes in a worse way.

\section{Discussion}

CMs are a heterogeneous group of disorders defined by anatomic anomalies of the cerebellum, brainstem, and CVJ, along with the downward displacement of the cerebellum, some-times accompanied by the lower medulla entering into the spinal canal ${ }^{[1]}$. They encompass a broad spectrum of neurodevelopmental disorders, some of which are unlikely to share com-mon pathophysiology [13].

The diagnosis of $\mathrm{CM}$ is performed neuroanatomically. There are no biomarkers in the blood, cerebrospinal fluid, or cultured tissue to confirm the diagnosis ${ }^{[1]}$. For this reason, neuroimaging is of prime importance, and MRI is the best imaging modality for evaluation ${ }^{[11]}$. Sagittal, coronal, and axial views of the brain, along with sagittal and axial images of the entire spinal cord (cervical, thoracic, and lumbar), using T1- and T2-weighted MRI sequences are useful in detecting cerebellar and brainstem displacement, associated craniocervical junction abnormalities, and $S M{ }^{[11]}$. The main reason for neurological abnormalities in these patients is SM. In CM-2 patients, the main reason for neurological deficits is MM and, therefore, paresis and plegia. This can be detected from birth using physical examination. The early recognition of SM is important for the prevention of the neurological deficits mentioned above. Thus, whole-spine MRI should be performed for all Chiari patients.

Various clinical and radiological characteristics are seen in the $\mathrm{CM}$ subgroups. Because $\mathrm{CM}-2$ is always accompanied by $M M$, it is detected and treated in the first months of life. Age at diagnosis is very early for CM-2 patients. CM-3 and CM-4 have completely different radiological and clinical features. The detection of these subgroups is performed at birth because their malformations are prominent on physical examination. The differences among CM sub-groups caused the variation of surgical procedures and then complications and prognosis.

The etiology and pathophysiology of Chiari are not wellunderstood. CM-2, CM-3, and CM-4 are believed to originate in the neuroectodermal tissue ${ }^{[10]}$.

In neuroectodermal originated CMs, additional diseases are seen more frequently, and early symptom appearance and surgery are more common. The duration of hospital stay is longer because a more complicated surgical procedure is performed. Interestingly, male predominance is seen in neuroectodermal originated CMs. Further investigation 
Table 3. Distribution of additional disease, syringomyelia existence, symptom duration, most common symp-toms, abnormal neuro examination and complication rate, hospital stay in neuroectodermal Chiari malformation subtypes

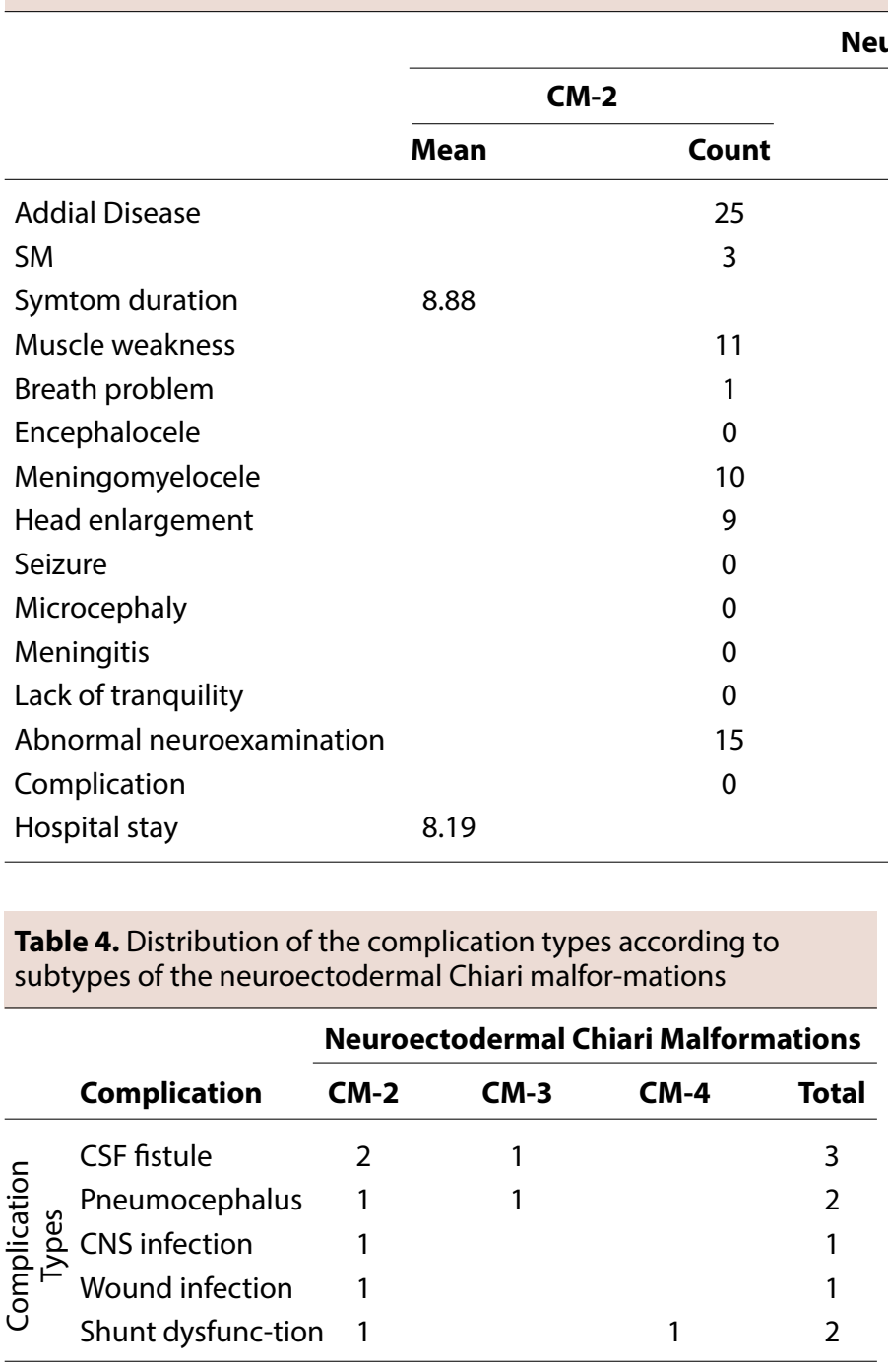

into sex and pathophysiology can reveal interesting results.

CM-2 is usually detected prenatally or at birth because it is nearly always associated with lumbosacral or thoracic myelomeningocele [1]. Manifestations in infancy may include dysphagia, arm weakness, stridor, apneic spells, and aspiration [14]. Progressive hydrocephalus is a common problem in CM-2 in late infancy and childhood [1]. In addition, CM-2 may be associated with one or more of the syndromes associated with CM-I, such as SM and scoliosis.

In our study, we conclude that the most common symptoms in CM are weakness in the extremities. The severity of symptoms varies according to the location and size of the neuronal damage. Paresis is very common in $\mathrm{CM}-2$ patients. In CM-3 patients, the most common symptom is acephalocele. In CM-4 malformation, the most common

pathology that accompanies cerebellar hypoplasia is hydrocephalus. Thus, the most common symptoms that patients seek medical advice are an increase in head size and restlessness.

SM is very rarely seen in CM-2 patients. SM is a pathology characterized by a cystic cavity in the spinal cord. Its incidence is reported to be 8.4 new cases/year/100.000 individuals ${ }^{[15]}$. Its etiology depends on four factors as follows: $\mathrm{CM}-1$, vertebral trauma, basilar invagination, and hydrocephalus ${ }^{[15]}$. Whatever the underlying pathology, the basic pathophysiology of SM is changes in physiological CSF flow dynamics. There is also a group of patients who do not belong to any of the etiologies mentioned. In this case, the SM is called 'idiopathic' ${ }^{\text {[16] }}$. Despite various hypotheses, the mechanisms of the formation and spontaneous resolution of SM remain controversial ${ }^{[17]}$.

The management of $\mathrm{CM}$ depends on the nature of the malformation and the degree of associated neurologic impairment. Particularly for $\mathrm{CM}-2$ and $\mathrm{CM}-3$, surgical interventions may include the closure of open neural tube defects shortly after birth, treatment for hydrocephalus (most often via the use of a shunt), and the decompression of tight posterior fossa structures ${ }^{[1,18]}$. The initial surgical treatment of $\mathrm{CM}-4$ malformation includes ventriculoperitoneal (VP) shunt placement, cystoperitoneal (CP) shunt placement, and combined VP and CP shunt insertion ${ }^{[19]}$. 
In our study, dural tear (CSF fistule) increases the risk of complications, infections, and reoperations. Also, hospital stay duration increases with the dural tear. In every case, the risk of complications increases following dural surgery because even with careful dural repair, it is difficult to control CSF fistula because of increased CSF circulation on the craniocervical junction and thoracolumbar region. In the same way, the presence of hydrocephalus in pa-tients with encephaloceles does not increase the risk of complication but does the increase mean hospital stay duration. Thus, any procedure on the dura of the CVJ and spine increases the risk of complications.

In the literature, The effects of SM in predicting the clinical outcomes could not be determined due to differences in the numbers of patients in the groups with and without SM ${ }^{[20]}$.

In our study, the symptom relief of patients differed significantly between subgroups. For this reason, surgical procedures and patient symptoms also vary. Due to meninomyeloceles and additional neurological deficits, the recovery of CM-2 patients is not satisfactory. Similarly, in patients with brain stem compression signs (as in patients with basilar invagination), symptoms may deteriorate despite surgery. In general, we can say that patients without brain stem compression signs, neurologic deficits, and additional diseases and patients who recover from simple surgical procedures have better outcomes. The duration of symptoms is one of the most important factors in symptom resolution. Early treatment is very important for these patients because, as the length of time since the initial appearance of symptoms increases, the rate of benefit from surgery decreases.

\section{Conclusion}

The long hospital stay, the presence of SM and short symptom duration are associated with worse outcomes. Dura repair is the most important stage of surgery. Dural tear (CSF fistule) increases the complication rate and mean hospital stay and causes the worse outcome. Therefore, the surgeon should spend more time on dura repair.

Ethics Committee Approval: Retrospective study.

Peer-review: Externally peer-reviewed.

Authorship Contributions: Concept: R.S.; Design: R.B.; Data Collection or Processing: R.B., N.I., M.E.; Analysis or Interpretation: R.S., R.B., N.I.; Literature Search: F.B.; Writing: R.S., R.B.

Conflict of Interest: None declared.

Financial Disclosure: The authors declared that this study received no financial support.

\section{References}

1. Sarnat HB. Disorders of segmentation of the neural tube: Chiari malformations. Handb Clin Neurol 2008;87:89-103.

2. Carmel PW, Markesbery WR. Early descriptions of the ArnoldChiari malformation. The contribution of John Cleland. J Neurosurg 1972;37:543-7. [CrossRef]

3. Pearce JM. Arnold chiari, or "Cruveilhier cleland Chiari" malformation. J Neurol Neurosurg Psychiatry 2000;68:13. [CrossRef]

4. Loukas M, Noordeh N, Shoja MM, Pugh J, Oakes WJ, Tubbs RS. Hans Chiari (1851-1916). Childs Nerv Syst. 2008;24:407-9.

5. Furuya K, Sano K, Segawa H, Ide K, Yoneyama H. Symptomatic tonsillar ectopia. J Neurol Neurosurg Psychiatry 1998;64:2216. [CrossRef]

6. Speer MC, Enterline DS, Mehltretter L, Hammock P, Joseph J, Dickerson M, et al. Review Article: Chiari Type I Malformation with or Without Syringomyelia: Prevalence and Genetics. J Genet Couns 2003;12:297-311. [CrossRef]

7. Boyles AL, Enterline DS, Hammock PH, Siegel DG, Slifer SH, Mehltretter $L$, et al. Phenotypic definition of Chiari type I malformation coupled with high-density SNP genome screen shows significant evidence for linkage to regions on chromosomes 9 and 15. American Journal of Medical Genetics Part A 2006;40(24):2776-85. [CrossRef]

8. Tubbs RS, Griessenauer CJ, Hendrix P, Oakes P, Loukas M, Chern JJ, et al. Relationship between pharyngitis and peri-odontoid pannus: A new etiology for some Chiari I malformations? Clin Anat 2015;28:602-7. [CrossRef]

9. Milhorat TH, Bolognese PA, Nishikawa M, McDonnell NB, Francomano CA. Syndrome of occipitoatlantoaxial hypermobility, cranial settling, and chiari malformation type I in patients with hereditary disorders of connective tissue. J Neurosurg Spine 2007;7:601-9. [CrossRef]

10. Schijman E. History, anatomic forms, and pathogenesis of Chiari I malformations. Childs Nerv Syst 2004;20:323-8. [CrossRef]

11. Caldarelli M, Di Rocco C. Diagnosis of Chiari I malformation and related syringomyelia: radiological and neurophysiological studies. Childs Nerv Syst 2004;20:332-5. [CrossRef]

12. Rozenfeld M, Frim DM, Katzman GL, Ginat DT. MRI Findings After Surgery for Chiari Malformation Type I. AJR Am J Roentgenol 2015;205:1086-93. [CrossRef]

13. Markunas CA, Tubbs RS, Moftakhar R, Ashley-Koch AE, Gregory SG, Oakes WJ, et al. Clinical, radiological, and genetic similarities between patients with Chiari Type I and Type 0 malformations: Clinical article. Journal of Neurosurgery: Pediatrics, 2012;9:372-8. [CrossRef]

14. Vandertop WP, Asai A, Hoffman HJ, Drake JM, Humphreys RP, Rutka JT, et al. Surgical decompression for symptomatic Chiari II malformation in neonates with myelomeningocele. J Neurosurg 1992;77:541-4. [CrossRef]

15. Di Lorenzo N, Cacciola F. Adult syringomielia: classification, pathogenesis and therapeutic approaches. Journal of neurosurgical sciences. 2005;49:65. 
16. KimJ, Kim CH, Jahng TA, Chung CK. Clinical course of incidental syringomyelia without predisposing pathologies. Journal of Clinical Neuroscience 2012;19:665-8. [CrossRef]

17. Kyoshima K, Bogdanov El. Spontaneous resolution of syringomyelia: report of two cases and review of the literature. Neurosurgery 2003;53:762-8. [CrossRef]

18. Ivashchuk G, Loukas M, Blount JP, Tubbs RS, Oakes WJ. Chiari
III malformation: a comprehensive review of this enigmatic anomaly. Childs Nerv Syst 2015;31:2035-40. [CrossRef]

19. Mohanty A, Biswas A, Satish S, Praharaj SS, Sastry KV. Treatment options for Dandy-Walker malformation. J Neurosurg 2006;105:348-56. [CrossRef]

20. Arora P, Behari S, Banerji D, Chhabra DK, Jain VK. Factors influencing the outcome in symptomatic Chiari I malformation. Neurol India 2004;52:470-4. 